Actis, B. \& Barberis, R. (2013). Las aulas de literatura. De los textos a la teoría y de la teoría a los textos. Rosario: Homosapiens. p. 164.

\title{
LA INTERACCIÓN ENTRE LOS TEXTOS Y LA TEORÍA EN LAS AULAS DE LITERATURA
}

Rosana Guardalá*

El modo en el que se enuncia el mundo, es sin duda un modo de pensar, de ver el mundo. Esta idea se manifiesta desde el título del libro. La pluralidad edilicia y simbólica (aulas) es el núcleo de una práctica docente que materializa el espacio de un saber multiplicado en la interpretación. El recorrido metodológico del libro también está explicitado en un diálogo en el que los textos toman la palabra. Si bien a lo largo de todo el libro la relación texto-teoría será constructiva y dialógica, no obstante es importante destacar aquí el punto de partida es la materia prima de la literatura: los textos en sus diversas formas genéricas.

El libro se divide en dos partes. La primera "Literatura en taller. Laboratorio de lecturas y escrituras", que coordina Beatriz Actis. La segunda bajo el título de "Análisis e interpretación de textos literarios: posicionamiento estratégico y operatoria" de Ricardo Barberis. Las partes de este libro conforman un todo que se articula metodológica y teóricamente. De modo que funcionan armónicamente como una suerte de par no dicotómico.

El libro abre una entrada múltiple a la escritura como práctica que no se agota en conocer y dominar los elementos lingüísticos. Saber (y poder) leer y escribir no son para Beatriz Actis y para Ricardo Barberis, así como tampoco para los que participan de este volumen, operaciones

*Profesora en Letras, egresada de la Facultad de Humanidades y Artes de Rosario (Santa FeArgentina), donde actualmente se desempeña como docente en la Cátedra de Análisis del Texto del Primer Año Común y en diversas Escuelas Secundarias. Participa como docente en el Posgrado en Educación para Extranjeros y ha dictado cursos en el Postítulo de Formación Universitaria en Lengua. Colabora tanto en revistas académicas y literarias como en medios periodísticos nacionales como internacionales. Forma parte de diversos proyectos de investigación. Actualmente está escribiendo su tesis Doctorado. En su investigación trabaja las subjetivizaciones femeninas textuales disidentes en la obra de Armonía Somers y Marosa di Giorgio. 
consecutivas ni mecánicas. Muy por el contrario, son prácticas solidarias que requieren de la reflexión teórica pero también metalingüística. Este libro se deshace de la idea del lenguaje por fuera del sentido común entendido como transparencia que reproduce la realidad y lo presenta en su complejidad y en su capacidad no sólo de representar sino también de crear realidades.

Es fundamental, antes de adentrarnos en las secciones mencionadas anteriormente, destacar el perfil del docente que se está pensando, con el que se pretende trabajar. En la introducción se toma posición con respecto al rol docente: "Las propuestas tienen como uno de sus objetivos potenciar aquella función intelectual: que la docencia indague sobre su condición de ser un trabajo en el que se produce intelectualmente, y por lo tanto pueda, en este caso, problematizar el rol del docente como sujeto lector y escritor, y no sólo como mediador de las prácticas de lecturas destinadas a los niños y jóvenes" (Actis y Barberis, 2013, 17). En pocas palabras, aquí el docente tiene un rol protagónico y novedoso en tanto no es sólo mero transmisor de conocimientos que luego serán evaluados. Esta construcción del rol docente es fundamental para animar y acompañar el trabajo con los estudiantes como productores de conocimientos, así como también como lectores y escritores críticos.

La primera parte del libro "Laboratorio ..." conjuga en esta forma dos discursos (literario-científico) e innova en la dinámica de taller. Este modo de nombrar propio de la ciencia sobreentiende la idea de ensayo, de prueba, de composición y de análisis. Así el espacio en el que habitualmente se manipulan seres vivos o partes de ellos, aparece aquí como un lugar de lectura, escritura y producción que pone el foco en los detalles, en la demora que requieren estos procesos. Este apartado se ramifica desde la división clásica de los géneros que toma como eje la poesía y la prosa. Comienza por declarar que no trabajará con textos edulcorados para los niños y jóvenes, sino que asume el desafío de abordar poetas como Marosa di Giorgio, Genovese, Calveyra y narradores clásicos y contemporáneos tales como Cortázar, Borges, Bolaño y de Santis, entre otros.

Todos los textos y fragmentos propuestos se articulan en la tríada lectura-juego-escritura. El aspecto lúdico de la literatura es fundamental 


\section{ROSANA GUARDALÁ}

en tanto habilita espacio de transformación (del poema en verso al poema en prosa) y movimientos (desde la biblioteca a otros espacios de la escuela), sólo por nombrar algunos. Es necesario recordar y nutrir el aspecto lúdico estrechamente ligado a la musicalidad y la polisemia del lenguaje para poder así volver al disfrute de la literatura. Es justamente desde allí donde el trabajo con la crítica y la traducción también tienen su lugar. Escribir es transformar pero también intervenir, experimentar, expandir los textos para comenzar a pensarlos como Textos en clave barthesiana. En este cruce los textos literarios, los críticos, las traducciones y las biografías flexibilizan los límites formales y abren el diálogo y el debate sobre el valor literario y su autonomía, sin plantearlo en términos explícitos.

Las actividades de esta primera parte son concretas pero no condicionan ni conducen al reconocimiento sino a la producción textual. También es destacable mencionar aquí que los textos como las propuestas muestran que se está pensando en un docente que pueda acompañar los procesos de lectura y escritura en los diferentes niveles, es decir, las actividades son pensadas con libertad y no están cercadas por las edades. Este trabajo editorial confía en el rol del docente intelectual, crítico y lector y en su interacción con los estudiantes. Por ello no es ambicioso proponer la lectura comparando diversas traducciones que no es más que un ejercicio crítico encubierto sobre el proceso de escritura y la importancia de la corrección. Así como tampoco es un gesto menor adentrarse en las microficciones, género poco transitado por la currícula escolar o "las redes de ficciones" que recupera dos conceptos claves y de profunda actualidad en el análisis literario: la intertextualidad y la interculturación.

Esta primera parte cierra con "Narrativas: experiencias de lecturas y escrituras" que toma un punto de partida doble: la TICs y biografías lectoras. El apartado referido a las nuevas tecnologías de la Información y la Comunicación se muestra como una clara lectura de los docentes que atienden a los movimientos culturales y sociales dentro y fuera del aula, en tanto gran parte de las propuestas surgen del mismo deseo o inquietud de los estudiantes. Así se arma un blog que resulta de un taller de lectura en el que no hay obligación de ningún tipo. En este misma línea vuelve 
el espacio lúdico bajo al forma del juego de rol como la posibilidad, por parte de los estudiantes, de interpretar y asumir papeles, acciones en una historia determinada. Interpretación que requiere atender no sólo al aspecto verbal sino también al contexto, a lo no verbal y a todo aquello que nos conduce irremediablemente a otro terreno con el que la literatura está ligado desde siempre: la vida. En este mismo cruce, Mery Cruz Calvo presenta, con acierto, "biografías lectoras". Se trata de una propuesta escrituraria que trasciende la biografía clásica que reúne datos para convertirla en textos significantes que se abren al sentido en tanto recogen “(...) testimonios de experiencias lectoras de docentes y futuros docentes (...)” (p.73), propiciando la reflexión sobre la incidencia de esas lecturas en las propias prácticas. Esta suerte de bio-bibliográficoafectivo que puede ser abordado desde un enfoque etnográfico, sin por ello desatender a la dimensión interlocutiva, temática y enunciativa del objeto en cuestión. Sin duda, esta propuesta aquí desplegada viene a revisar los límites entre lo literario, lo pedagógico, lo antropológico y lo histórico.

En "Análisis e interpretación de textos literarios: posicionamiento estratégico y operatoria", Ricardo Barbieri, desde el comienzo, explicita que el análisis y la interpretación son actividades complejas. Con ello nos coloca frente a las implicancias teóricas y operativas a las que no podemos dejar de atender. Parte de una serie de situaciones hipotéticas de lectura que nos demuestran que "Ese modo particular (uno entre otros posibles) de entender el texto literario, así como la posición teórica que lo sustenta, está comprometido en cada consigna de trabajo, en cada operación de lectura". Barbieri observa que lo sepamos o no, nuestra lectura está siempre atravesada por nociones teóricas y críticas; y acuerda con Bombini, quien plantea que la teoría literaria no debe ser pensada como objeto de la enseñanza independiente sino articulado a partir de las preguntas de los textos literarios. Preguntas de este tipo pero también sobreentendidas son las que aparecen estructurando este apartado: qué lector pretendemos y qué lector somos; en qué consiste el análisis de una obra literaria; en qué consiste interpretar una obra literaria; qué hacer con los textos canónicos. La primera de ellas es la que despliega entre el presente y el futuro la posibilidad de abrir otros espacios. Un lector que no sólo pueda unir sílabas, reconocer o 


\section{ROSANA GUARDALÁ}

identificar temas sino y sobre todo, un lector que sea capaz de armar su propia lectura crítica no individual o psicologista.

Barberis, con claridad, afirma que "Toda operación de lectura que propiciamos como docentes implica: 1. Un modo de concebir el hecho literario y el lenguaje. 2. La superposición o convocatoria de un marco teórico o de una reflexión literaria. 3. Una determinada idea del rol del lector en formación. 4. Un perfil del lector que somos como mediadores" (p. 107). En esta suerte de declaración aparecen conjugados ciertos organizadores de la operación entendida como la ejecución de acciones y los que en ella participan: sujetos que saben, que conocen, que intuyen teorías y sujetos que saben, que conocen y que median entre ese saber. En ambos casos, estudiante y docente, son ante todo lectores.

Esta segunda parte cierra con la lectura interpretativa de "El cautivo" de Jorge Luis Borges. Con agudeza y claridad allí se despliegan las operaciones de lectura y los lugares de incomodidad o tensión teórica (tema, argumento, historia, verosimilitud, enunciación literaria, entre otros) que se propusieron anteriormente. La construcción de la hipótesis de lectura, núcleo de la interpretación, está indisolublemente ligada a la argumentación. Cómo se compone la interpretación, cómo se sostiene, hasta dónde se puede interpretar son las preguntas que perimentan el trabajo.

Las aulas de lengua y literatura. De los textos a la teoría y de la teoría a los textos es un libro que abre propuestas en y para el aula. Esta publicación se corre de los lugares de confort e invita mediante una doble entrada no jerarquizada práctica-teoría a conocer, recorrer un nuevo corpus de escritores y poetas, así como también a revisar con otra mirada el canon escolar. Este libro propone una serie de actividades y lecturas novedosas pero sobre todo posibles en tanto experiencias realizadas en el aula, producto de las prácticas de un docente que se hace cargo de su rol intelectual y, por lo tanto, cuida del avance de las teorías y de la articulación de éstas con las lecturas. No desatender a las categorías de análisis, a la interpretación pero explicitando y asumiendo puntos de vistas claros es ir hacia el lector que pretendemos en un nosotros (en términos de Benveniste) inclusivo, en el que el docente y el estudiante caminen juntos. 